\title{
La otra evasión: libros y lectura para prisioneros durante la Primera Guerra Mundial*
}

\author{
Alfonso González Quesada \\ Universitat Autònoma de Barcelona
}

RESUMEN: El presente artículo estudia un fenómeno poco explorado por la historiografia de la Gran Guerra: la organización de bibliotecas y servicios de lectura para prisioneros. Se parte del problema que supuso para los paises beligerantes la atención a un número de cautivos sin precedentes. Su auxilio mediante el suministro de libros evidenció un perfil de combatiente distinto al de conflictos anteriores: en su mayoría, hombres alfabetizados y familiarizados con la lectura. Se describe el tejido institucional que intervino en la selección y envio del material, así como las vicisitudes y obstáculos que se debieron superar para distribuirlo en los campos de internamiento. Destacan tres tipologías de obras: religiosas, textos instructivos y prensa. Se valora la significación que tuvieron entre los prisioneros. En la elaboración del artículo se han consultado fuentes bibliográficas, hemerográficas y archivísticas.

\section{Palabras Clave: Libros; Lectura; Prensa; Bibliotecas; Prisioneros; Primera Guerra Mundial.}

\section{The other escape: books and reading to prisoners during World War I}

ABSTRACT: This article studies a largely unexplored phenomenon by the historiography of the Great War: the organization of libraries and reading services to prisoners. The starting point is the problem that represented for the belligerent countries the aid to a number of prisoners without precedents. Its aid through reading supplies demonstrated a combatant profile different from any previous war. Most men were literate and familiar with reading. The article describes the institutional network that took part in the selection and shipping of reading material, as well as the vi-

* Siglas de Archivos: Archivo General de Palacio (Madrid). 
cissitudes and obstacles that should be overcome to distribute it. Three main types of reading are emphasized: religious works, instructive texts and press, and its meaning among the men is valued. In the preparation of the article it had been consulted bibliographical and archival sources.

KeY WORDS: Books; Reading; Press; Libraries; Prisoners; Great War.

\section{INTRODUCCIÓN}

En La grande illusion, el clásico de Renoir que retrata las peripecias de un grupo de prisioneros franceses en Alemania, hay una secuencia singular. El entusiasmo se desata entre los oficiales rusos al saber que han recibido de su zarina una caja enorme. La alegría les empuja a querer compartir el regalo con sus compañeros de internamiento, convencidos de que contiene alimentos y bebida. Pero el entusiasmo se desvanece cuando descubren qué esconde la caja. La sorpresa es mayúscula. Está repleta de libros: tratados morales, de aritmética, hay incluso uno de cocina. La sorpresa deriva en indignación y ésta desemboca en alboroto hasta el extremo de que los oficiales rusos, ante el estupor de los franceses, acaban quemando los libros. La secuencia, más allá de una interpretación chauvinista - la civilidad gala contrapuesta a la rudeza rusa-, acepta otra: leer no era una prioridad en el cautiverio. Sus condiciones de vida imponían cubrir necesidades más perentorias (alimento, medicinas, vestido, etc.). Sin embargo, libros y prensa circularon intensamente entre los prisioneros y, aunque sea imposible ofrecer un dato exacto, no sería exagerado aventurar que su número rondó los diez millones de documentos.

Ningún conflicto había reunido antes a tantos hombres que supieran leer. Aunque fue una aptitud extendida de forma desigual entre los ejércitos, cuando la guerra se prolongó más de lo previsto, todos organizaron servicios de lectura para procurar a sus combatientes libros y revistas adecuadamente seleccionados. El envío de lectura a los campos de internamiento formó parte de aquella movilización colosal del mundo del libro. Las circunstancias de los prisioneros, ajenas a las de cualquier otro escenario del conflicto, confirieron un perfil distintivo a lo que pudieron leer. La historiografía apenas se ha ocupado del tema. El presente artículo pretende aportar algo de luz sobre él, intentando responder a un conjunto de cuestiones: cuál era el tejido organizativo que intervino en el suministro de lectura; qué instituciones destacaron en ese cometido; qué vicisitudes y obstáculos enfrentaron; cuáles fueron los materiales más leídos y qué significación tuvo para los prisioneros.

Para responder a estas preguntas se ha recurrido a la consulta de tres tipos de fuentes. El primero corresponde a los testimonios directos, como memorias de prisioneros y de quienes intervinieron en su auxilio. En el segundo se 
incluyen las fuentes hemerográficas coetáneas a la contienda que han aportado datos de interés sobre los servicios de lectura en los centros de reclusión. El último es material bibliográfico dedicado a estudiar la situación de los prisioneros. Aunque su objetivo no fuera analizar la significación que la lectura tuvo para aquellos hombres, las referencias a esta cuestión han resultado de inestimable valor. Este cúmulo de datos, testimonios y documentos no puede reconstruir íntegramente la experiencia lectora de los prisioneros, pero ha permitido elaborar un relato que, a pesar de ser incompleto, intenta explicar con claridad y rigor la magnitud de un fenómeno prácticamente inexplorado.

La aproximación a una temática tan específica debe contextualizarse en el marco de otros estudios que han abordado el conflicto desde perspectivas distintas, aunque no excluyentes. El primero al que conviene referirse comprende las obras dedicadas a la noción de «cultura de guerra» ${ }^{1}$. Los campos de prisioneros serían un resultado más de esa «cultura», entendida como conjunto de sistemas simbólicos y de representación de un colectivo, cuyo objetivo era construir una identidad opuesta a la del enemigo para destruirlo. Odio, violencia y horror fueron instrumentos de la «cultura de guerra». Y no cesaron de aplicarse tras la rendición y la captura del enemigo. Durante su cautiverio adoptaron nuevas formas, como muestra del proceso totalizador del conflicto. Un segundo tipo de trabajos corresponde a los que han descrito la vida cotidiana del combatiente, especialmente aquellos que han hecho hincapié en los procesos de sociabilización mediante la organización de todo tipo de actividades (culturales, recreativas, deportivas, religiosas...) $)^{2}$. Un tercer conjunto de estudios es el dedicado a la historia cultural del conflicto, concretamente los que se han interesado por la representación de la guerra a través de la prensa para soldados ${ }^{3}$. Por último, cabe citar las aportaciones que han dado a conocer la significación de la experiencia lectora entre los combatientes y la organización de servicios de lectura durante el conflicto ${ }^{4}$.

${ }^{1}$ Sobre el concepto de cultura de guerra: AUDOIN-ROUZEAU y BECKER, 1997. AUDOIN-ROUZEAU y BECKER, 2000. En torno a este libro véase PROST, 2002. BECKER, 2010. DUMÉNIL, BEAUPRÉ e INGRAO, 2004; BECKER, 2005.

2 Sobre la vida cotidiana del soldado francés: MEYER, 1966. CAZALS y LOEZ, 2008. SOUDAGNE, 2009. Sobre los combatientes belgas: AMEZ, 2009. Ámbito anglosajón: FULLER, 1990. Soldados australianos: LAUGESEN, 2011.

${ }^{3}$ Prensa italiana: ISNENGHI, 1977. Prensa francesa: AUDOIN-ROUZEAU, 1968; Jean-Jacques BECKER, 1984. Prensa alemana: NELSON, 2011. SEAL, 2013.

${ }^{4}$ Servicios de lectura estadounidenses: YOUNG, 1981. Entorno francés: MULLER, 2000. Alemania: FUCHS, 2008. Para una panorámica global sobre los servicios de lectura durante el conflicto: Alfonso González, 16/30 (Lejona, 2011): 229-245. 


\section{LA DIMENSIÓN DEL PROBLEMA}

Durante la guerra se tomaron cerca de ocho millones de prisioneros ${ }^{5}$, dos tercios de ellos en el frente oriental. Cifras inimaginables en los albores del conflicto, pese a que desde las primeras ofensivas se comenzase a percibir la magnitud del problema, agravado cuando fue evidente que las hostilidades se prolongarían más allá de lo previsto. En agosto de 1914 ningún contendiente disponía de la infraestructura suficiente para transportar, dar cobijo, vestir y alimentar la avalancha humana a la que poco después debería hacer frente. Soluciones precipitadas e improvisación fueron norma en los meses iniciales. El caso de Rusia es ilustrativo, aunque no el único. Tuvo que habilitar como centros de reclusión, desde granjas y mataderos, hasta fábricas abandonadas, escuelas e incluso cárceles 6 , y no pocos de los soldados apresados tardaron meses en llegar al lugar donde transcurriría su confinamiento ${ }^{7}$.

Es cierto que ser capturado eliminaba el riesgo de morir en combate, pero no de perecer a causa del hambre, maltrato o enfermedad, especialmente en los primeros años de guerra. Alrededor de tres cuartos de millón de hombres murieron durante su internamiento ${ }^{8}$. Un dato elocuente sobre la dureza del cautiverio. Con el tiempo, las condiciones de vida mejoraron gracias a la labor humanitaria de diversas organizaciones. Sin embargo, en algunos países el curso del conflicto influyó negativamente en la situación de los prisioneros. En Alemania, el bloqueo económico que agudizó la escasez general también se extendió a los campos, mientras que en Rusia, la anarquía tras la revolución supuso abandonar a su suerte a más de dos millones de hombres.

Al sufrimiento físico se añadía el moral. El sentimiento de culpa, la vergüenza por el deshonor, el temor al abandono y al olvido mermaban el equilibrio anímico. El confinamiento era un doble exilio: lejos de la patria y lejos de la patria en guerra ${ }^{9}$. En un entorno marcado por la incertidumbre y la angustia de una reclusión prolongada, cualquier intento de recrear cierto nivel de sociabilidad en los campos, o de establecer vínculos con un universo ajeno al conflicto, fue valioso. Y la lectura, de cartas o de libros, sirvió para ello. Si bien no fue el antídoto para el deseo de la evasión física, leer ayudó a construir un refugio interior y a sobrellevar las penurias del internamiento. Nunca antes se leyó ni se escribió tanto, porque en ninguna guerra habían combatido tantos soldados lectores.

\footnotetext{
5 WINTER, 2010.

${ }^{6}$ DAVIS, 1983: 167-168.

7 RACHAMIMOV, 2002: 49.

8 STIBBE, 41/1 (London, 2006): 5.

9 AUDOIN-ROUZEAU, BECKER, 2000: 96.
} 


\section{EL TEJIDO INSTITUCIONAL}

Un amplio conglomerado de sociedades, asociaciones y comités canalizó las aportaciones económicas y las donaciones de editores, bibliotecas, universidades y particulares para hacer llegar libros y revistas a los centros de internamiento. Gran parte de ese conglomerado ya proporcionaba lectura a combatientes y hospitales militares. Es el caso, por ejemplo, de la Camps Library, que colaboró con el Central Prisoners of War Committee de la Cruz Roja Británica. Algunas iniciativas contaban con experiencia en la organización de ayuda a los ejércitos. Die Tientsiner Hilfsaktion, fundada por Elsa von Hanneken, había auxiliado a principios de siglo a las tropas europeas en China en la revuelta de los bóxers, y durante el conflicto incluyó lectura entre el material con que socorrió a los alemanes y austríacos internados en Siberia ${ }^{10}$. Otras instituciones habían acumulado sólidas trayectorias en el suministro de libros a las tropas, como la Société Franklin, que desde finales del siglo XIX se había dedicado a crear bibliotecas para los militares franceses. Durante la guerra reunió libros y revistas para combatientes y cautivos. Desde países neutrales también se pusieron en marcha iniciativas que, si bien no tenían como objetivo principal el envío de lectura, lo incluyeron en sus tareas de auxilio a los prisioneros, como la Mission Catholique Suisse. En España, la Oficina Pro Cautivos remitió a través de sus embajadas alrededor de 40.000 volúmenes de literatura, ciencia y arte para quienes conocieran nuestro idioma $^{11}$. Hubo entidades creadas ex profeso para atender las necesidades de lectura de los prisioneros y que tras el conflicto desaparecieron, como el comité surgido en Estocolmo en 1916, que envió a Rusia alrededor de 100.000 libros $^{12}$. Incluso las hubo que se especializaron solo en suministrar material para el estudio en los campos. Sin embargo, por encima del resto y merced a su vocación universal, destacaron dos: Cruz Roja y Young Men's Christian Association (YMCA).

\section{El Comité Internacional de la Cruz Roja}

Dos semanas después de comenzar la guerra, el Comité Internacional de la Cruz Roja (CICR) solicitó a los comités nacionales su colaboración en las actividades que organizaría en pro de las víctimas. En relación con los prisioneros, en ninguna de las convenciones del CICR anteriores al conflicto (Gi-

${ }^{10}$ BRÄNDSTRÖM, 1928: 196-197.

${ }^{11}$ Envíos de libros a los prisioneros, Archivo General de Palacio (Madrid), (Oficina pro cautivos), caja 12111, exp. 30, fol. 4 .

12 BRÄNDSTRÖM, 1928: 190. 
nebra, 1906 y La Haya, 1907) se había elaborado una reglamentación precisa sobre las condiciones de su cautiverio. Durante los primeros meses, el CICR actuó amparado en una resolución de su conferencia internacional de Washington de 1912, que no había sido ratificada por los contendientes ${ }^{13}$. La creación de la Agencia Internacional de Prisioneros de Guerra, a finales de agosto de 1914, permitió al CICR disponer de un instrumento que centralizase la información sobre los cautivos y gestionase el envío de ayuda material ${ }^{14}$.

Antes de que 1914 concluyera, delegados del CICR y representantes de potencias neutrales obtuvieron la autorización de los beligerantes para visitar sus centros de reclusión. La guerra de movimientos había propiciado la captura de cientos miles de prisioneros en ambos bandos. Solo en la batalla de Tannenberg, los alemanes apresaron a 92.000 rusos $^{15}$; en el Marne, 30.000 germanos cayeron en poder de los franceses. Gracias a aquellas visitas, el CICR pudo conocer de primera mano las condiciones de detención de los prisioneros y demostrarles que no estaban abandonados a su suerte ${ }^{16}$. En enero de 1915 emitió una circular con la que pretendía garantizar un trato idéntico para todos ellos en cuestiones relativas a trabajo, higiene, alimentación, envíos de dinero y correspondencia ${ }^{17}$. Fue novedosa la mención expresa de proporcionar lectura a los prisioneros. Por primera vez en su historia el CICR planteaba algo semejante. Los libros debían ser en la lengua de los internados $\mathrm{y}$, sobre todo, ajustarse a las limitaciones impuestas por las autoridades militares que, de forma común, prohibieron textos referidos a la contienda o con contenido político. La circular también aconsejaba a los comités de la Cruz Roja de los países en guerra que elaboraran listas de títulos o de categorías de obras cuya distribución fuese aceptada en los centros de reclusión.

Las recomendaciones en materia de lectura de la circular de enero de 1915 se fueron aplicando gradualmente, e incluso complementando con reglamentaciones particulares. Así, en abril Serbia permitió a los oficiales austrohúngaros disponer de pequeñas bibliotecas ${ }^{18}$. En agosto, el Ministerio de la Guerra francés aceptó los envíos para los prisioneros alemanes ${ }^{19}$; mientras que Italia, que había entrado en guerra en mayo de 1915, tras las dos primeras ofensivas del Isonzo contra el ejército austrohúngaro, autorizó a oficiales y tropa a disponer de los libros y revistas que proporcionasen las bibliotecas de las locali-

\footnotetext{
13 DURAND, 1978: 51-52. BECKER, 1998: 182.

${ }^{14}$ HAROUEL, 1999: 38.

15 STRACHAN, 2001: 331.

${ }^{16}$ HAROUEL, 1999: 40-41.

${ }_{17}$ Bulletin International des Societes de la Croix-Rouge, 46/181 (Genève, 1915): 5.

${ }_{18}$ Bulletin International des Societes de la Croix-Rouge, 46/181 (Genève, 1915): 253.

${ }^{19}$ Bulletin International des Societes de la Croix-Rouge, 46/181 (Genève, 1915): 497.
} 
dades próximas a los centros de internamiento ${ }^{20}$. Sin embargo, una cuestión era el espíritu de aquellas reglamentaciones y otra muy distinta su aplicación efectiva, que siempre quedó en manos de la comandancia de los campos.

Antes de que se pudiera hablar de una organización más o menos sistemática y regular del suministro de lectura, en algunos campos habían surgido bibliotecas informales, constituidas a partir de los libros que los soldados tenían consigo y de los enviados por familiares. Los acuerdos entre los contendientes para el trato recíproco de prisioneros contribuyeron a consolidar y extender los servicios de lectura, a la vez que fijaron los límites de lo que podía entrar en los campos y en qué condiciones. Así, en la Conferencia de Estocolmo, celebrada en noviembre de 1915 entre representantes de la Cruz Roja de Alemania, Austria-Hungría, Turquía y Rusia, se decidió que los prisioneros podrían recibir libros, siempre que se tratara de ejemplares nuevos, editados antes de 1913 y sin ningún tipo de signos, anotaciones o dibujos. Las obras en lenguas poco habituales fuera de su ámbito natural debían incluir la traducción del título en francés ${ }^{21}$. Por su parte, los Imperios Centrales exigieron a los británicos que el material no contuviera información sobre el curso del conflicto, mapas, ni comentarios sobre las potencias contra las que el Reino Unido combatía. Las revistas ilustradas fueron muy apreciadas en los campos, sin embargo, solo se aceptaron los números publicados antes de junio de 1914 y que no incluyeran imágenes, dibujos o caricaturas alusivas a los contendientes ${ }^{22}$. Pudieron enviar lectura tanto las organizaciones autorizadas por los beligerantes como los particulares. A éstos, las autoridades solían exigir que los libros se hicieran llegar sin la encuadernación, porque en más de una ocasión se había utilizado para introducir mapas u objetos prohibidos en los campos ${ }^{23}$.

Además de los comités de la Cruz Roja de las naciones en guerra colaboraron los de algunos países neutrales. El danés sobresalió en el suministro de lectura en el frente oriental, tanto por el número de documentos que expidió como por la eficiencia de su trabajo. Inició su labor en 1915, tras la Conferencia de Estocolmo ${ }^{24}$. Dispuso de una sección específica, donde un equipo de docentes y bibliotecarios seleccionaba los libros y otro se encargaba de prepararlos para su expedición. Una tarea minuciosa porque cada ejemplar debía ser revisado para eliminar páginas en blanco, anotaciones o signos y

${ }^{20}$ Bulletin International des Societes de la Croix-Rouge, 46/181 (Genève, 1915): 463.

${ }^{21}$ Bulletin International des Societes de la Croix-Rouge, 47/185 (Genève, 1916): 133. RACHAMIMOV, 2002: 76-77.

22 HOFFMAN, 1920: 79.

${ }^{23}$ RACHAMIMOV, 2002: 77.

${ }^{24}$ «La Croix-Rouge danoise en 1915», Bulletin International des Societes de la CroixRouge, 48/189 (Genève, 1916): 78-79. DURAND, $1978: 31$. 
evitar, así, que en el país de destino la censura frustrase el envío. La Cruz Roja Danesa mandó más de 800.000 volúmenes a cientos de campos rusos, alemanes y austrohúngaros. Ningún otro comité nacional alcanzó cifras similares. También fue singular el número de peticiones individuales que atendió. Al finalizar la contienda su registro contenía más de 20.000 fichas de soldados lectores ${ }^{25}$.

\section{Young Men's Christian Association (YMCA)}

Diversos países neutrales representaron los intereses de los beligerantes durante el conflicto. En materia de prisioneros, esa representación suponía recabar información sobre su paradero, inspeccionar centros de reclusión y supervisar la compra y distribución de ayuda material para los confinados. Tales cometidos recaían en las embajadas, carentes de la infraestructura y los recursos para organizar un auxilio capaz de mejorar de forma sustancial las condiciones de vida de aquellos hombres y, sobre todo, faltas de la experiencia y el personal adecuado con que contaba el comité americano de $\mathrm{YMCA}^{26}$.

YMCA surgió en Inglaterra a mediados del siglo XIX, con la intención de alejar a la juventud trabajadora de las grandes urbes de vicios como la bebida, el juego y la prostitución. Su alternativa a la corrupción moral pasaba por el fortalecimiento de la mente, el cuerpo y el espíritu, mediante la creación de bibliotecas, la organización de actividades lúdicas y educativas y la lectura y el estudio de la Biblia. La filantropía paternalista de YMCA pronto se extendió fuera del Reino Unido y al estallar el conflicto era la organización cristiana más influyente en el mundo protestante. Cuando en agosto de 1914 la Alianza Mundial de YMCA decidió trabajar en todos los frentes para atender a combatientes, heridos y prisioneros, el comité americano era el que se encontraba en la mejor disposición para intervenir, no solo porque contaba con recursos financieros suficientes y con la experiencia adquirida en conflictos anteriores, sino también por el respaldo del presidente Wilson ${ }^{27}$.

YMCA vio en el desastre de la guerra una oportunidad histórica para globalizar su misión evangelizadora. De ahí que no se contentase solo con procurar lo necesario para el culto de las diferentes confesiones que convivían en los campos. Sus esfuerzos se concentraron en mejorar las condiciones de vida de los prisioneros, y en dinamizar su día a día organizando actividades educativas, deportivas y culturales. El prestigio que cosechó fue el resultado de una

25 «La Section des livres de la Croix-Rouge danoise», Bulletin International des Societes de la Croix-Rouge, 48/192 (Genève, 1916): 425-427.

26 STEUER, 2008: 6.

27 STEUER, 2008: 34-38. 
labor misionera y filantrópica universal, destinada a todos los hombres, fuese cual fuese su credo, estuviesen recluidos en Europa, o lejos de ella.

Sin embargo, ni la caridad cristiana que guiaba la misión de YMCA ni la neutralidad del comité americano fueron aval suficiente para superar la oposición inicial que despertó su trabajo en pro de los prisioneros. Las autoridades militares no ocultaron su temor ante la amenaza de espionaje que representaba la entrada de los delegados de YMCA en los campos. Además, los países católicos la veían como un instrumento de propaganda y proselitismo protestantes, mientras que los sectores más progresistas desconfiaban del sectarismo religioso que podía amagar ${ }^{28}$. El elemento que disipó buena parte de las reticencias fue la aplicación que hizo del principio de reciprocidad entre los beligerantes. Tal principio establecía, para el caso de Francia y Alemania, por ejemplo, que el trato recibido por los cautivos alemanes en territorio francés sería idéntico al dado a los franceses en suelo germano. YMCA negoció su acceso a los campos sobre la base de aquel principio. El éxito de su estrategia diplomática fue remarcable. A mediados de 1916, con la excepción de Turquía, YMCA trabajaba en favor de los prisioneros de todos los países en conflicto ${ }^{29}$.

\section{BIBLIOTECAS Y SERVICIOS DE LECTURA}

Como señala Keegan, la guerra en 1915 ya no se parecía en nada a lo que habían visto o esperado quienes luchaban desde el inicio del conflicto ${ }^{30}$. La guerra de movimientos había dado paso a una guerra de posiciones, donde un sinfín de trincheras surcaba el terreno entre Bélgica y Suiza como una cicatriz infinita. El número de enemigos había crecido, así como los escenarios de la lucha, que no se limitaban a la tierra firme. Bajas y prisioneros se contaban por millones y lo peor es que la esperanza de una victoria rápida se había desvanecido. En aquel contexto, la primavera de 1915 supuso un punto de inflexión para el establecimiento de bibliotecas y servicios de lectura. A partir de entonces los envíos de libros, si no fueron constantes, se hicieron mucho más frecuentes. A ello contribuyó la puesta en marcha de las principales iniciativas del tejido institucional, pero no fueron menos importantes factores como el fin de bloqueo postal a los cautivos y la gratuidad en el franqueo ${ }^{31}$. De nada hubieran servido los esfuerzos de aquel variado complejo organizativo sin la colaboración de los servicios postales. Baste un dato para revelar su

\footnotetext{
${ }^{28}$ STEUER, 2008: 75, 86, 99.

${ }^{29}$ STEUER, 2008: 63-65.

${ }^{30}$ KEEGAN, 1999: 204.

${ }^{31}$ PANDO, 2002: 159.
} 
significación: solo el servicio suizo envió gratuitamente a los prisioneros cerca de 500 millones de cartas y paquetes ${ }^{32}$.

En abril de 1915 el comité americano de YMCA inauguró su primera instalación. Fue en Alemania, en el campo de Göttingen. Ocupaba unos 200 metros cuadrados, con espacios para impartir clases, una pequeña cocina y una habitación que hacía las veces de sala de lectura y biblioteca. A finales de aquel año ya contaba con más de 7.000 volúmenes en distintas lenguas ${ }^{33}$. Después de Göttingen, se levantó una construcción similar en otra ciudad germana, Crossen-an-der-Oder. El interés que despertó la biblioteca entre los prisioneros, la mayoría rusos, lo demuestra el ritmo de préstamos tras su apertura. El centenar del día inaugural se triplicó solo dos días después ${ }^{34}$.

Hacia mediados de 1917 gran parte de los 165 campos repartidos por Alemania tenía biblioteca. En algunos casos su colección reunía varios miles de volúmenes, como la de Rastatt, con una circulación diaria de 200 libros. Sin embargo, no en todos los países la presencia de bibliotecas estuvo tan extendida. En Rusia, de sus casi 900 centros de internamiento solo una minoría contó con aquel servicio. YMCA instaló bibliotecas en 40 de los 68 campos donde trabajó ${ }^{35}$. Hubo algunas muy bien dotadas, como la de Krasnoyarsk, con 200.000 volúmenes, o la de Berezovka, formada en su mayoría por los fondos de la biblioteca de la fortaleza de Przemysl, llevados consigo por los más de 110.000 austrohúngaros que se rindieron a los rusos en marzo de $1915^{36}$, después de soportar el que sería el asedio más largo de toda la contienda ${ }^{37}$.

La lectura y el uso de bibliotecas constituyeron actividades habituales entre los oficiales. Sus condiciones de internamiento, comparadas con las de la tropa, hicieron del cautiverio una experiencia privilegiada, no solo porque los centros de reclusión y el régimen de vida fuesen distintos para ambos, sino porque en muchos casos los soldados tuvieron que trabajar para el enemigo.

El testimonio del teniente coronel Luxmoore Newcombe, quizá ayude a comprender mejor cómo eran y funcionaban las bibliotecas en los campos para oficiales ${ }^{38}$. Newcombe fue capturado en mayo de 1917 en Chemin des Dames, tras la fallida ofensiva aliada para romper las líneas alemanas ${ }^{39}$. Durante un mes estuvo recluido en Rastatt, donde intentó combatir el aburri-

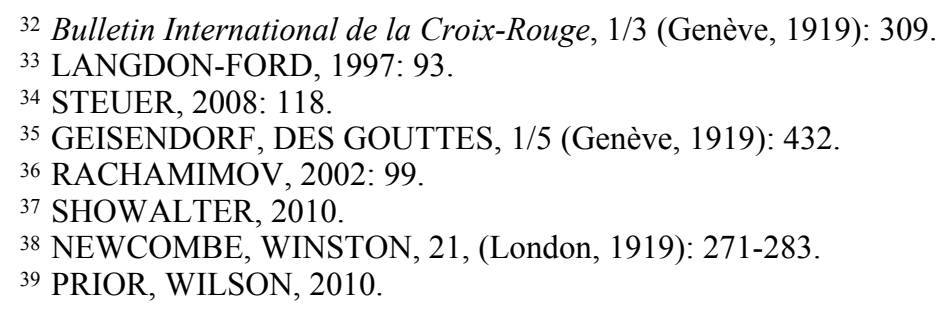


miento con los pocos libros que se vendían en la cantina a un precio prohibitivo. En junio fue transferido a Straslund, junto a varios cientos de oficiales británicos. Pronto decidió poner en marcha con otro compañero una biblioteca. Obtener el permiso de la comandancia del campo no fue tan costoso como adecentar el espacio cedido. A finales de julio la biblioteca abrió sus puertas. Contaba con sala de lectura para una veintena de personas y un pequeño depósito, donde estaba organizado el millar escaso de libros que las autoridades germanas facilitaron. Los lectores - 467 en su inicio- pagaban una cuota mensual. La biblioteca disponía de un reglamento que fijaba el horario (abría todos los días alrededor de tres horas, en dos turnos: por la mañana y a última hora de la tarde); regulaba el préstamo; preveía la posibilidad de listas de espera e incluso establecía multas por retrasos en las devoluciones. El uso frecuente y la falta de encuadernación de muchas obras agravaron su deterioro, amenazando con echar a perder parte de la colección. Para evitarlo se logró improvisar un taller de encuadernación, a pesar de las grandes restricciones que imponía el bloqueo. El fondo se enriqueció considerablemente gracias a los envíos de YMCA, la Cruz Roja Danesa y el British Prisoners of War Book Scheme. También las cuotas de los lectores se emplearon para comprar centenares de obras, y los propios prisioneros cedieron a la biblioteca las que recibían personalmente o tenían consigo. Ese volumen, que en la firma del armisticio sumaba 2.576 obras, contribuyó también a proporcionar lectura al hospital del campo.

A diferencia de los oficiales, la tropa fue obligada a trabajar. La convención de La Haya permitía la utilización de prisioneros como mano de obra. Rusos y alemanes los emplearon a gran escala. En Rusia llegaron a suponer la mitad de los efectivos de ciertas empresas; en Alemania, dos terceras partes de los internados fueron enviados a explotaciones agrícolas, minas o fábricas $^{40}$. Para muchos hombres el trabajo mejoró sus condiciones de vida, en especial, su alimentación. En cambio, limitó el acceso a la lectura. Para paliar tal situación se crearon bibliotecas circulantes, compuestas por pequeñas colecciones, renovadas periódicamente y enviadas a destacamentos de trabajo y centros de internamiento que no disponían de biblioteca ${ }^{41}$. En ocasiones se hicieron reimpresiones de las obras más solicitadas para proporcionar algo interesante que leer a quienes marcharan a los destacamentos de trabajo. ${ }^{42}$ Con el transcurso de la guerra aumentaron los servicios de lectura itinerante. La Oeuvre des Bibliothèques pour Prisonniers Isolés fue una de las iniciativas de este tipo. Organizada en 1918 por la Cruz Roja Francesa en colaboración

40 BECKER, 1998: 112.

${ }^{41}$ For the millions of men now under arms, 8, (New York, 1916): 31-32. HOFFMAN, 1920: 123 .

${ }^{42}$ For the millions of men now under arms, 8, (New York, 1915): 39. 
con YMCA, destinó a los internados en Alemania 450 cajas con un total de 9.000 volúmenes ${ }^{43}$.

\section{OBSTÁCULOS A LA LECTURA}

Aunque la distribución de libros alcanzase cifras millonarias, eso no quiere decir que estuviera exenta de obstáculos y dificultades, ni que todos los prisioneros tuvieran a su alcance algo que leer durante su cautiverio. La composición multinacional de las tropas austrohúngaras y los contingentes coloniales de británicos y franceses hicieron de sus ejércitos verdaderos mosaicos lingüísticos. Una pluralidad que, trasladada a los campos, dificultó la obtención de lectura para algunos grupos, como indios, senegaleses o argelinos, aunque es cierto que, tanto su número como sus niveles de analfabetismo, limitaron la demanda de textos. Tampoco fue sencillo proporcionar lectura a los otomanos internados en Rusia. Solo en aquellos campos cercanos a zonas tártaras se pudieron conseguir libros y prensa en turco ${ }^{44}$. El mayor problema fue la escasez de textos en lenguas eslavas y, en especial, en ruso. Ante su déficit constante, YMCA decidió reproducir obras ya existentes que contaran con el visto bueno militar. A partir de 1916 optó por publicarlas directamente ${ }^{45}$. Para ello reclutó a escritores y traductores que también adaptaron su trabajo a los límites de la censura. Mayoritariamente, se trató de textos destinados a la alfabetización, ya que tres de cada cuatro rusos no sabían leer ni escribir. También la alta aristocracia intentó aliviar la falta de lectura para sus nacionales. La princesa Helena de Altenburg, que se había destacado por hacer de su palacio un hospital para heridos ${ }^{46}$, intervino en la organización de diversos envíos. El de junio de 1917, meses después de abdicar el zar y en plena efervescencia revolucionaria, incluyó más de 400.000 libros ${ }^{47}$. Sin embargo, la escasez reapareció al acabar la guerra, cuando el Alto Mando aliado ordenó al gobierno alemán detener la repatriación de prisioneros para no engrosar las filas del ejército surgido de la revolución. En consecuencia, hacia enero de 1919 permanecían en Alemania 400.000 rusos. YMCA intentó contrarrestar la extensión entre ellos de la propaganda bolchevique, mediante las lecturas que consiguió en los países vecinos de la nueva república soviética y a través de imprentas de Berlín y Berna.

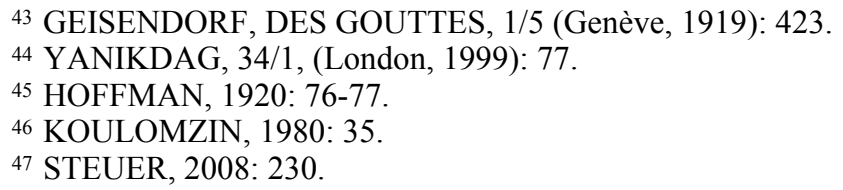


Hacer llegar el material a los campos también obligó a solucionar las dificultades que cada situación planteaba. YMCA agilizó el suministro de lectura a Francia y Alemania al establecer un programa de intercambio entre ambos países. Primero se gestionó desde la biblioteca de Stuttgart y más tarde desde Berna $^{48}$. En Rusia, la censura retuvo en exceso los envíos de la Cruz Roja Danesa hasta que la organización fijó una delegación en Petrogrado para evitar el retraso en la distribución de libros y comprobar que éstos llegaban a su destino $^{49}$. Otras entidades actuaron de intermediarios, como la Société Bibliographique de París, que colaboró en el examen de los libros para los prisioneros franceses en Alemania, y ayudó al comité de la Cruz Roja de Rouen ante las dificultades que encontró para su expedición.

La escasez de textos en ciertas lenguas, el rigor de la censura o los problemas inherentes a la distribución de lectura no fueron los únicos obstáculos que impidieron leer a muchos hombres. Quedaba la prohibición; fruto en ocasiones del recelo o el temor, infundado o exagerado. En Omsk, las autoridades prohibieron la lectura de libros sobre siderurgia por considerarlos políticamente peligrosos ${ }^{50}$. Los responsables del campo de Stralsund, convencidos de que tras la guerra el Reino Unido estrecharía lazos comerciales con Rusia, no permitieron a los británicos tener gramáticas rusas para evitar el estudio de aquella lengua ${ }^{51}$. La prohibición fue también una actitud discriminatoria. El paneslavismo ruso explica porqué en el Turquestán, donde la mayoría de prisioneros era de origen eslavo, se impidió el estudio y la lectura de textos en alemán ${ }^{52}$. Pero en la mayoría de los casos se recurrió a la prohibición como forma de represalia. En marzo de 1917, ante los rumores que llegaron al Ministerio de Guerra del Reich sobre el trato desfavorable a sus militares, los cautivos franceses no recibieron lectura hasta que no se tuvo conocimiento de la mejora de las condiciones en los campos de Francia ${ }^{53}$. Sin duda, el castigo más flagrante fue el que aplicaron las autoridades austrohúngaras a sus propios soldados. Uno de cada cuatro movilizados cayó prisionero; la proporción más grande entre todos los ejércitos que combatieron ${ }^{54}$. Como se ha señalado, el austrohúngaro era un conglomerado nacional, donde casi la mitad de sus efectivos eran eslavos ${ }^{55}$. En las campañas de la Galitzia de 1914 y 1915, los rusos capturaron varios cientos de miles de soldados, y 400.000 en la ofensiva

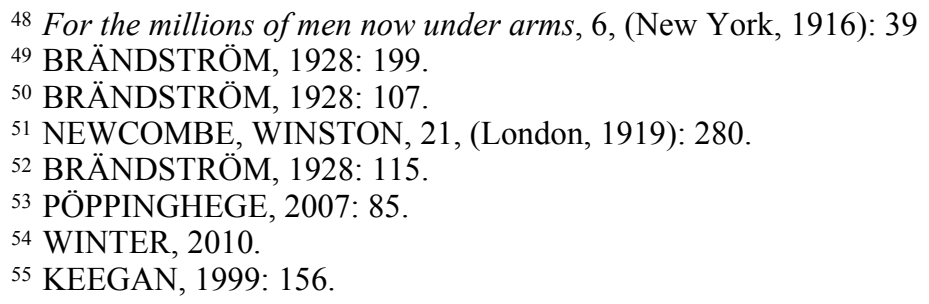


de Brusilov, de $1916^{56}$. Las autoridades de Viena atribuyeron aquellas cantidades de prisioneros checos, serbios, y ucranianos a deserciones en masa, antes que a la incompetencia militar de sus generales y, en respuesta a lo que consideraron deslealtad a la monarquía, se negaron a que se les proporcionara ningún tipo de lectura ${ }^{57}$.

\section{LECTURAS RELIGIOSAS}

El libro religioso entró temprano en los campos. Diversas razones lo explican. La primera tiene que ver con su presencia entre los combatientes desde el inicio del conflicto. Son numerosos los testimonios al respecto. Nadeshda Krupskaya, la compañera de Lenin, recuerda cómo en los días de la movilización general, en la estación de Cracovia, grupos de monjas repartían imágenes y libros de oración a los polacos que marchaban al frente ${ }^{58}$. A principios de 1915 la prensa británica informó que la Biblia se había traducido a tres nuevas lenguas, entre ellas el nepalí, para hacerla llegar a los regimientos gurkha que luchaban en Francia ${ }^{59}$. Tras la misa en el frente, los soldados italianos solían acercarse al capellán en busca de textos piadosos ${ }^{60}$. Incluso los turcos internados en campos franceses recibieron ejemplares del Corán para reemplazar los perdidos en combate ${ }^{61}$. ¿Lectura?, ¿talismán?, o ¿ambas cosas? Fuera lo que fuese, el libro religioso acompañó, primero en el frente y después en el cautiverio, a cientos de miles de hombres. Una segunda razón está relacionada con el perfil confesional de muchas de las organizaciones que auxiliaron a los prisioneros y con el objetivo inicial de su labor: el consuelo espiritual, en el que las celebraciones litúrgicas jugaron un papel importante. Hay también otro aspecto que ayuda a explicar la enorme presencia del libro religioso, y que no se debe soslayar. Su contenido levantaba entre las autoridades militares, recelosas siempre de la lectura en los campos, menos sospechas que ningún otro.

Desde la primavera de 1915 hasta la conclusión de la guerra se distribuyeron varios millones de biblias católicas y protestantes, evangelios, libros de salmos, y demás obras piadosas o morales. Durante tiempo fue el único material con el que las autoridades austrohúngaras permitieron aliviar el tedio en

56 KEEGAN, 1999: 304.

57 STEUER, 2008: 332.

${ }^{58}$ KRUPSKAYA, 1976: 235.

59 «1.500.000 Bibles. Demands of the armies of the belligerants», The Times, 10 de marzo de 1915.

${ }^{60}$ MOROZZO, 8/4, (Torino, 1979): 499.

${ }^{61}$ GEISENDORF, DES GOUTTES, 1/5, (Genève, 1919): 433. 
sus campos ${ }^{62}$. A finales de 1915, tras la ofensiva sobre el puerto de Salónica para socorrer al ejército serbio, ${ }^{63} \mathrm{el}$ número de biblias y evangelios se hizo insuficiente para atender la demanda de ingleses y franceses recluidos en Bulgaria. YMCA solicitó entonces la colaboración de las sociedades bíblicas británica y americana y de la World's Sunday School Association, que aportaron cientos de miles de ejemplares con los que paliaron la escasez de Sagradas Escrituras $^{64}$. Más adelante se dio la misma situación con los prisioneros rusos y se recurrió a la Sociedad Bíblica de Berlín para conseguir textos en su lengua $^{65}$.

El hecho de que los primeros envíos de evangelios y libros de rezo se agotasen rápidamente fue percibido por las iglesias como el renacer de un nuevo fervor religioso, cuando más bien -sin negar la posibilidad de conversiones espectaculares-, respondiera a la necesidad de ocupar el tiempo con algo que reconfortara el espíritu. En cualquier caso, la movilización de las diferentes iglesias jugó un papel esencial en el sostenimiento anímico de los cautivos. Proporcionar lectura fue una estrategia común a todas ellas, impuesta por el apremio de responder al desastre moral que representaba una guerra entre naciones cristianas. Una estrategia en la que, a la postre, se hizo visible la competencia entre organizaciones católicas y protestantes, ya que el propósito de la lectura iba más allá de la simple acción caritativa.

En el caso de YMCA, bajo su estrategia ecuménica y universalista subyacía el afán proselitista inherente a toda misión evangelizadora, reflejada en el inequívoco cariz protestante de las lecturas que proporcionó. Un buen ejemplo es la obra del teólogo Alexandre Westphal, Jesús de Nazareth, publicada en 1915, traducida a seis idiomas y ampliamente distribuida entre los prisioneros $^{66}$. Por otro lado, evangelios, libros de oración y diccionarios bíblicos se destinaron a la liturgia y a la acción pastoral, desarrollada mediante grupos de lectura y estudio de textos religiosos. No extraña que para muchos hombres las instalaciones de YMCA ocuparan el centro de la vida espiritual de los campos.

Por otro lado, la declaración de neutralidad de la Santa Sede le impidió intervenir directamente en el auxilio de los prisioneros y contrarrestar la influencia que ejercían sobre ellos organizaciones protestantes como $\mathrm{YMCA}^{67}$. No obstante, la jerarquía católica se movilizó para enviar lectura a los cauti-

62 STEUER, 2008: 86.

${ }^{63}$ SHOWALTER, 2010. POPE, WHEAL, 1995: 418.

${ }^{64}$ STEUER, 2008: 69, 149-150.

${ }^{65}$ HOFFMAN, 1920: 77.

${ }^{66}$ GEISENDORF, DES GOUTTES, 1/5 (Genève, 1919): 433.

${ }^{67}$ BECKER, 1998: 314. 
$\operatorname{vos}^{68}$. Hubo iniciativas individuales, como la del nuncio apostólico de Munich, que reunió varios miles de libros para los soldados italianos, o las de los obispos de Vilnius, Kaunas, Bucarest y Varsovia, que mandaron textos a lituanos, rumanos y polacos ${ }^{69}$. Sin embargo, ninguna de aquellas iniciativas alcanzó la envergadura del trabajo de la Mission Catholique Suisse y la alemana Kirchliche Kriegshilfe.

Sostenida por católicos franceses, la Mission Catholique Suisse se puso en marcha en enero de 1915, a instancias de las autoridades de la Confederación Helvética y con el apoyo tácito del Vaticano, hecho que permitió sortear su neutralidad. La organización suiza cubrió lo que consideraba la falta de literatura piadosa para los prisioneros, mediante la edición de la hoja Dieu et l'Église, la distribución de prensa católica y de medio millón de libros calificados de 'edificantes' 70 . Intentó así compensar la enorme difusión de lecturas hecha por YMCA y Cruz Roja. Además, creó una biblioteca ambulante para los capellanes, con la que asegurar la celebración del culto católico en los campos que atendió repartidos por Suiza, Francia y Alemania. El suministro de libros se llevó a cabo gracias a la colaboración de religiosos de dentro y fuera de los campos y, especialmente, de la Borromeusverein, la principal asociación católica alemana, dedicada durante el Segundo Reich a crear salas de lectura y bibliotecas para la población, y que medió entre las autoridades militares y la Mission Catholique Suisse ${ }^{71}$.

Desde el momento en que empezaron a llegar los primeros prisioneros a los campos cercanos a Paderborn, el obispo de la diócesis creó Kirchliche Kriegshilfe. Como otras entidades similares cumplió las tareas de obtener información sobre el paradero de combatientes desaparecidos y proporcionar ayuda moral y material a los cautivos. La hizo singular que fuera la única organización de un país en guerra ocupado de las víctimas de ambos bandos. También facilitó la labor pastoral de los sacerdotes recluidos en campos franceses, con el envío regular del sermón que debían impartir. Hacia 1916 destinaba semanalmente alrededor de 600 copias. Kirchliche Kriegshilfe instaló bibliotecas en diversos campos, y surtió a muchas otras con lecturas que debían proteger 'contra la amargura y la desesperanza, la duda religiosa y la inmoralidad' 72 . Aunque no excluyera libros recreativos e instructivos, el grueso de las obras que proporcionó fue de contenido religioso. Para los prisioneros aliados editó hojas similares a Dieu et l'Eglise, en flamenco e italiano, de las

\footnotetext{
${ }^{68}$ DURAND, 1978: 60.

${ }^{69}$ STRAKE, 1/5 (Genève, 1919): 521.

70 BEAUPIN, 1/5 (Genève, 1919): 529.

71 YERLY, 58/2 (Paris, 1998): 21.

72 STRAKE, 1/5 (Genève, 1919): 523.
} 
que distribuyó, en conjunto, tres millones de ejemplares ${ }^{73}$. También publicó libros de rezo en las principales lenguas de los internados en suelo alemán, con tiradas que superaron las 100.000 copias. Los cautivos germanos, además de cientos de miles de libros de plegaria, recibieron himnarios, prensa religiosa y miles de ejemplares de Imitación de Cristo de Tomás de Kempis. Hasta la primavera de 1919 Kirchliche Kriegshilfe había realizado envíos por valor de un millón de marcos de la época.

\section{LECTURA Y ESTUDIO}

La consideración de prisionero de guerra no se limitó a los combatientes. Miles de deportados y, quienes en el inicio de las hostilidades se encontraban en territorio enemigo, fueron recluidos en centros de internamiento. También para ellos la lectura fue refugio y alimento, pero no solo espiritual. Militares y civiles hicieron del cautiverio un tiempo de estudio. Sin el apoyo del libro nunca hubiera sido posible que muchos de ellos superaran el analfabetismo, enriquecieran su cultura, e incluso retomaran las carreras que el conflicto había truncado.

Del variado universo de entidades y organizaciones que enviaron material de lectura, hubo algunas que se especializaron en proporcionar obras para el estudio. La Deutsche Christlicher Studenten Vereine instaló bibliotecas con literatura técnica y profesional en diversos campos alemanes. Se estima que, gracias a su labor, unos 20.000 soldados siguieron su formación durante el cautiverio ${ }^{74}$.

Después de casi un año de guerra y tras las sucesivas derrotas ante el ejército alemán, el número de rusos prisioneros era descomunal. Solo en las dos batallas de los lagos Masurianos fueron capturados unos 200.000 hombres $^{75}$. Ante aquella situación, en el verano de 1915 comenzó a trabajar en Londres un comité para destinar lectura a los rusos confinados en Alemania. Formaban parte de él un bibliotecario de la London Library y un reducido número de rusos residentes en Inglaterra ${ }^{76}$. El comité dio respuesta a peticiones de civiles y militares. Fueron muchas más las de libros instructivos que las de obras de ficción. Por esa razón se priorizó el envío de manuales técnicos ${ }^{77}$. El material fue adquirido a través de editoriales rusas, gracias a las aportaciones de particulares y de la colaboración de una organización holandesa, cuyo fin

\footnotetext{
${ }^{73}$ STRAKE, 1/5 (Genève 1919): 520.

74 STEUER, 2008: 147.

75 KEEGAN, 1999: 173. STRACHAN, 2001: 332-335. SHOWALTER, 2010.

76 «Books for russian prisoners», The Times, 31 de agosto de 1915: 9.

77 «Books for russian prisoners», The Times, 31 de agosto de 1915: 11
} 
era idéntico al del comité británico ${ }^{78}$. La revolución en Rusia truncó su actividad, aunque hasta inicios de 1917 logró mandar más de ocho toneladas de volúmenes a cerca de un centenar de campos alemanes ${ }^{79}$.

En septiembre de 1916, dos meses después del inicio de la ofensiva británica en el Somme, la prensa londinense ${ }^{80}$ dio a conocer el proyecto del Camp Education Department para crear una biblioteca destinada a los prisioneros británicos y de la Commonwealth que quisieran estudiar y obtener una titulación universitaria. Tras el visto bueno del Foreign Office a la iniciativa, los responsables del British Prisoners of War Book Scheme, así se denominó el servicio, hicieron un llamamiento a la población para que colaborase con libros o aportaciones económicas para adquirirlos. A finales de 1916 publicó una relación con las obras más necesarias; mayoritariamente textos instructivos o de perfil académico ${ }^{81}$. Los libros se enviaron de forma gratuita en respuesta a las solicitudes de los prisioneros, repartidos en más de 200 campos de Alemania, Austria, Bulgaria, Turquía, Suiza y Holanda ${ }^{82}$. Hacia 1917 se habían recibido alrededor de 10.000 peticiones y el número de volúmenes enviados superaba los $55.000^{83}$.

El funcionamiento de la Oeuvre Universitaire Suisse des Étudiants Prisonniers de Guerre fue muy similar al servicio británico. Desde 1915 y hasta el final del conflicto, sus diferentes comités organizaron bibliotecas, salas de estudio y conferencias, además de proporcionar cerca de 100.000 volúmenes a más de 13.000 franceses y a prisioneros de otras nacionalidades confinados en Alemania, Francia, Austria e Italia. Delegados daneses y holandeses atendieron a los estudiantes recluidos en el Reino Unido, Alemania y Rusia ${ }^{84}$.

Aprovechar el cautiverio aprendiendo idiomas fue algo común, especialmente en aquellos campos que se convirtieron en pequeñas babeles al reunir a combatientes de diferentes procedencias. En el ruso de Novonikolaievsk se llegaron a enseñar catorce lenguas distintas, incluyendo el turco, hebreo y esperanto ${ }^{85}$. Sin embargo, las autoridades zaristas vieron con desconfianza el aprendizaje del ruso, porque creían que su conocimiento incitaría a la evasión $^{86}$.

${ }^{78} \mathrm{KOCH}, 1919: 282$.

79 HAGBERG WRIGHT, 22, (Chicago, 1917): 274-276.

80 «Books for russian prisoners», The Times, 26 de septiembre de 1916: 11.

${ }^{81}$ Library World, 18, (London, 1916): 160. LANGDON-FORD, 6/1, (1997): 95.

82 «Books for prisoners», The Times, 29 de diciembre de 1916.

${ }^{83} \mathrm{KOCH}, 1919: 240$.

${ }^{84}$ Bulletin International des Societes de la Croix-Rouge, 48/192, (Genève, 1917): 475476. DEHERAIN, 1919: 10.

${ }^{85}$ YANIKDAG, 34/1, (London, 1999): 76.

${ }^{86}$ BRÄNDSTRÖM, 1928: 119. 
Por iniciativa de Alfonso XIII y financiada con su propio dinero, la Secretaría particular del rey organizó la Oficina Pro Cautivos, un «templo de misericordia» desde el que se contribuyó a «aliviar los dolores y suavizar los sufrimientos de las más variadas gentes de los países en guerra» ${ }^{87}$, trabajando para evitar represalias, conmutar penas capitales, canjear heridos y suministrar medicamentos, alimentos y libros a los prisioneros de ambos bandos. Desde finales de 1915 la embajada española en Berlín recibió peticiones de lectura de franceses internados en Alemania. Solicitaban libros y revistas ilustradas en español porque conocían el idioma y muchos de ellos buscaban sobre todo un apoyo a las clases de español que impartían. La embajada no disponía de ningún tipo de material con que satisfacer aquellas demandas, así que las trasladó al barón d'Anthouard, presidente de la Cruz Roja Francesa ${ }^{88}$. En diciembre de 1915, el barón comunicó al embajador, Luis Polo de Bernabé, que la organización que presidía tampoco podía atender aquellas peticiones y le informaba que las remitía a la Société Bibliographique ${ }^{89}$, con la esperanza de que aquella institución pudiera conseguir el material solicitado. Un año después, la Oficina comenzó a enviar a la embajada en Berlín obras donadas por la Asociación de la Librería Española. El secretario particular de Alfonso XIII, al anunciar a Polo de Bernabé la puesta en marcha de la iniciativa, destacó su significación:

permitirá no solamente realizar una obra humanitaria (...) sino también una obra patriótica cual es la de difundir el conocimiento de nuestro idioma y de nuestros mejores autores presentes y pasados, en circunstancias tales que harán difícil, si no imposible el olvido de uno y de otros ${ }^{90}$.

Los primeros envíos contuvieron mayoritariamente clásicos españoles y, aunque fueron siempre bien recibidos, el embajador señaló que las lecturas preferidas por los prisioneros eran los textos de divulgación científica y los libros de viajes ${ }^{91}$.

En ciertos campos la oferta formativa no se limitó a los idiomas. Fue mucho más amplia, hasta el punto que los prisioneros hablaban de 'universidades'. Abelardo Pérez, un voluntario español internado en Darmstadt explica

87 BRÄNDSTRÖM, 1928: 153

${ }^{88}$ Carta de Luis Polo de Bernabé al barón d'Anthouard, 15 noviembre 1915, Archivo General de Palacio (Madrid), (Oficina pro cautivos), legajo 671.

${ }^{89}$ Carta del barón d'Anthouard a Luis Polo de Bernabé, 1 diciembre 1915, Archivo General de Palacio (Madrid), (Oficina pro cautivos), legajo 671.

${ }^{90}$ Carta de Emilio $\mathrm{M}^{\mathrm{a}}$ de Torres a Luis Polo de Bernabé, 6 febrero 1917, Archivo General de Palacio (Madrid), (Oficina pro cautivos), legajo 671.

${ }^{91}$ Carta de Luis Polo de Bernabé a Emilio Ma de Torres, 16 mayo 1917, Archivo General de Palacio (Madrid), (Oficina pro cautivos), legajo 671. 
que se encargó «la formación de la universidad al soldado francés Debordes, que era abogado de profesión» y añade que «el comité danés de la Cruz Roja fue quien envió cuanto se necesitaba: libros, gramáticas, diccionarios, plumas y pinceles $\rangle^{92}$. El cuadro de asignaturas de Darmstadt incluía literatura, derecho mercantil, música, dibujo, pintura y mecanografía. En Rusia, austríacos y alemanes organizaron escuelas donde impartir todo tipo de disciplinas, gracias a los dos millones de libros que recibieron. Antes de ese aluvión bibliográfico, los únicos libros disponibles solían estar en ruso. Pero el interés por leer y estudiar fue tal, que quienes sabían algo de aquella lengua los tradujeron para sus compañeros. Elsa Brändström, que colaboró como enfermera de la Cruz Roja Sueca, señala cómo ese inmenso flujo de lectura, unido al afán por el estudio y aprendizaje que suscitó, transformaron los campos siberianos en polos de civilización y cultura, capaces de rivalizar con las grandes ciudades de la región ${ }^{93}$.

Pero si hubo un campo conocido por su 'universidad', ese fue el de Ruhleben, cercano a Berlín, donde los prisioneros, en su mayoría civiles británicos, además de desarrollar una amplia gama de actividades culturales y disfrutar de instalaciones deportivas, organizaron un sistema escolar que atendió a un millar largo de hombres, mediante cursos sobre múltiples materias. El profesorado lo componían docentes de universidades próximas e internados con buena formación ${ }^{94}$. YMCA facilitó el equipamiento para los laboratorios de física, química y biología, y contribuyó a enriquecer la biblioteca. Para ello fue esencial el acuerdo que alcanzó con la Biblioteca Real de Berlín, por el que ésta prestaba el material bibliográfico que los prisioneros precisaban renovándolo periódicamente ${ }^{95}$. Acuerdos similares se establecieron con diversas bibliotecas universitarias para proporcionar lectura a los campos de Heidelberg y Villingen ${ }^{96}$. La biblioteca de Ruhleben abrió sus puertas en noviembre de 1914. Fijó normas de uso y elaboró informes sobre su actividad. Así se conoce que comenzó con algo menos de 400 libros, los primeros fueron donados por el embajador estadounidense, y 350 lectores. Casi un año después de ponerse en funcionamiento publicó su catálogo, que vendía por un marco, y que contenía más de 2.000 títulos ${ }^{97}$.

La revolución que sacudió Rusia también propició la lectura y el estudio entre los prisioneros de ambos bandos. La dureza del cautiverio hizo muy proclives a húngaros y alemanes a la influencia de la propaganda política. La

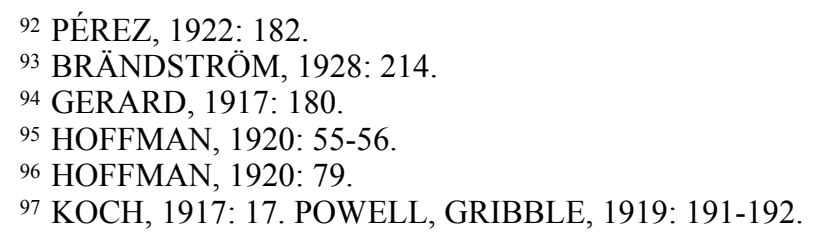


esperanza en que el triunfo de la revolución pusiera fin a la guerra y les devolviese la libertad empujó a muchos de ellos a leer, traducir y estudiar textos marxistas y bolcheviques. Por otro lado, la guerra civil, que siguió a la Revolución de Octubre y que asoló el país, prolongó el internamiento en Alemania de cientos de miles de rusos hasta 1920. Esos años de internamiento sirvieron para erradicar el analfabetismo entre los prisioneros; ya fuera porque unos asumieron que la construcción de una nueva sociedad pasaba por el aumento de su nivel de formación y se volcaron al estudio, o bien porque otros simplemente reaccionaron ante el rumor de que el gobierno soviético no aceptaría la repatriación de quienes no supieran leer y escribir ${ }^{98}$.

\section{Prensa Para CaUtivos}

La guerra era nuestro único pensamiento. Sabíamos cómo iba porque teníamos periódicos franceses, suizos y alemanes que los soldados nos proporcionaban clandestinamente. Estos periódicos nos costaban, por ejemplar, de 10 a 50 marcos. Se formaban grupos para compartirlos. Y eran leídos en voz alta. Centenares de prisioneros escuchábamos anhelantes ${ }^{99}$.

Son palabras de Valentín Torras, un obrero español internado en Chemnitz, donde convivieron prisioneros militares y civiles. Su testimonio aporta detalles significativos. El primero demuestra que la prensa era de difícil acceso en los campos alemanes. El segundo ilustra la necesidad incontenible de leer para conocer la marcha del conflicto, hasta el extremo de pagar una fortuna por un diario. En 1915, con 10 marcos se podía comprar un centenar de ejemplares. El tercero, que la lectura de prensa podía ser una experiencia colectiva, hecha de viva voz, ya fuera por la escasez de ejemplares, porque alguien traducía del original o porque se leía para quien no sabía hacerlo.

La lectura de diarios no se reguló de manera uniforme en todos los campos. En algunos fue prohibida, como revela el testimonio de Torras; en Francia estuvo limitada a los oficiales, mientras que en otros lugares apenas encontró obstáculos. Ante esta disparidad de situaciones cabe preguntarse si, al margen de la prensa convencional, los prisioneros leyeron otro tipo de prensa. La dinámica del cautiverio y de la guerra permiten distinguir tres: la elaborada por los propios internados; la procedente de organizaciones confesionales y la que actuó como medio de propaganda para influir políticamente en los campos.

98 STEUER, 2008: 310-311.

99 TORRAS, 1916: 88. 


\section{Prensa elaborada por prisioneros}

Así como hubo prensa de trincheras, la hubo también de prisioneros. $\mathrm{Su}$ misión inicial fue informar sobre el curso del conflicto, a menudo mediante la traducción y el comentario de noticias de diarios locales que entraban en los campos, o a través del testimonio de prisioneros recién llegados. Cuando se hizo evidente que la guerra no tendría un desenlace inminente, este tipo de prensa dejó de referirse a ella y para hacer más llevadero el cautiverio, intentó mantener vivo el recuerdo de la patria tiñendo de humor retratos y semblanzas de la vida cotidiana. Gerald Davis ha destacado la labor, cercana al periodismo local, de muchos de los colaboradores del medio centenar de publicaciones alemanas que aparecieron en Rusia, y que hizo de ellas un valioso instrumento para mitigar el desasosiego que provocaba el rumor ${ }^{100}$.

Siempre que periódicos y revistas no tratasen temas políticos ni incluyeran contenidos ofensivos para el enemigo, las autoridades militares permitieron su publicación, máxime cuando valoraron su lectura como una forma provechosa de ocupar el ocio y, en consecuencia, como un aliado en el mantenimiento del orden. Algunos periódicos aparecieron muy temprano, como el alemán Kirgisische Grenzbote. Lo hizo en septiembre de 1914 en el campo de Akmolinsk, en Asia Central ${ }^{101}$. Sin embargo, la prensa elaborada por los prisioneros creció cuando la organización y funcionamiento de los campos ganó estabilidad y los transformó en pequeñas urbes con actividades culturales y recreativas con cierto nivel de consolidación. También hubo dos condiciones que a menudo determinaron quiénes podían poner en marcha proyectos semejantes: el tiempo para escribir y el dinero con el que sufragar los costes de publicación, dos condiciones siempre más habituales entre la oficialidad.

En noviembre de 1914, Le Petit Journal se hizo eco de la aparición en Zossen de Le Héros, una hoja humorística que buscaba mantener la alegría y la esperanza en el cautiverio ${ }^{102}$. El diario parisino recordaba que aquella iniciativa no era una novedad; retomaba la tradición inaugurada por los franceses capturados durante la guerra de 1870. Aunque la mayoría de periódicos fuera como Le Héros, fruto del trabajo de prisioneros de la misma nacionalidad, otros fueron el resultado de la colaboración de hombres de procedencias distintas, lo que se tradujo en algunos casos en la circulación de una misma cabecera en varios idiomas, como sucedió en Göttingen, donde sus tres diarios se editaron en inglés y francés ${ }^{103}$. Los de Göttingen eran impresos, pero no en todos se dispuso del mismo nivel de recursos e infraestructura, por eso

100 DAVIS, 1983: 180.

101 WUNZER, $2000: 208$.

102 «Le journal des prisonniers de guerre français», Le Petit Journal, 24 de noviembre de 1914: 3 .

${ }^{103}$ STEUER, 2008: 119. 
muchos periódicos fueron manuscritos, elaborados artesanalmente, copiados y vendidos, e incluso enviados fuera de los campos para ofrecer, allá donde llegasen, una visión esperanzada del cautiverio.

\section{Prensa distribuida por organizaciones confesionales}

Un número considerable de boletines parroquiales surgieron por iniciativa de los capellanes de los campos, pero el grueso de los periódicos de contenido religioso y moral corrió a cargo de YMCA y la Mission Catholique Suisse. Desde 1915, esta última, además de la citada Dieu et l'Eglise, envió a Francia dos publicaciones en alemán, sufragadas por el obispo de Padernborn: Kirchenglocken, una revista bimensual, que tiraba 33.000 ejemplares, y la hoja semanal Sonntagspredigten, para la labor litúrgica de los capellanes ${ }^{104}$.

YMCA contribuyó a la edición de publicaciones como Journal du Prisonnier Polonais, salida de la imprenta del campo francés de Puits-Pardès, donde estaban internados soldados checos, polacos y búlgaros ${ }^{105}$. La prolongación de la guerra persuadió a YMCA de la necesidad de una revista que llegase al máximo número de lectores para fortalecer su moral y ampliar su instrucción. Con esos objetivos apareció a partir del verano de 1915 Messager du Prisonnier de Guerre, con ediciones en inglés, francés y alemán, y una tirada mensual de 45.000 ejemplares ${ }^{106}$. Su popularidad obligó a publicarla también en ruso y búlgaro. Messager incluía artículos recreativos y morales sin excluir la nota humorística, además de contenidos instructivos como apoyo a los cursos impartidos en muchos campos. Su trayectoria se prolongó tras el armisticio, distribuyéndose hasta marzo de 1920 entre quienes permanecieron recluidos.

\section{Prensa y propaganda política}

Los captores utilizaron la prensa para influir en los prisioneros y obtener algún rédito moral o militar. Abelardo Pérez explica que antes de ser interrogado, un oficial alemán le dio un periódico en francés, Gazette des Ardennes:

Me causó gran asombro que allí hubiera diarios en ese idioma, mas pronto advertí al ver sus caricaturas y leer su texto que se trataba de un diario de propaganda alemana (...) Pintábase ahí a los peludos andrajosos y hambrientos. Un dibujo daba a entender que Francia carecía de municiones ${ }^{107}$.

104 BEAUPIN, 1/5, (Genève, 1919): 530.

105 GEISENDORF Y DES GOUTTES, 1/5, (Genève, 1919): 430.

106 GEISENDORF y DES GOUTTES, 1/5, (Genève, 1919): 424-425.

107 PÉREZ, 1922: 175. 
Además de Gazette des Ardennes, distribuida en campos de internamiento y zonas ocupadas, los alemanes editaron otras cabeceras ${ }^{108}$, como Continental Times y Journal for Americans in Europe ${ }^{109}$. Una de las más significativas fue el semanario Le Camp de Göttingen, la publicación oficial de los campos del Reich ${ }^{110}$. Estaba destinada a belgas y franceses y solía incluir artículos elogiosos sobre Alemania, además de proporcionar información sobre el curso de la guerra. Sin embargo, como demuestra el testimonio de Abelardo Pérez, el escepticismo entre sus lectores fue notorio.

Fue común intentar subvertir la lealtad de los prisioneros de ciertas nacionalidades para crear unidades que combatieran contra sus propios ejércitos. En ese contexto de instrumentalización de la identidad nacional debe entenderse el fomento del paneslavismo entre los serbios, checos y eslovacos prisioneros de los rusos, así como la autorización que éstos concedieron a agitadores checos para distribuir en sus campos literatura nacionalista ${ }^{111}$, con el objetivo era reclutar voluntarios para el ejército de la futura Checoslovaquia independiente del Imperio austrohúngaro.

Hasta la abdicación del zar, en marzo de 1917, las autoridades alemanas no impidieron que entre los prisioneros rusos circulase la prensa de organizaciones revolucionarias en el exilio. Confiaban en que su discurso antibelicista calase en los campos y se extendiera a los frentes. Tras la marcha de Nicolás II, el compromiso del gobierno de Kerensky de proseguir la lucha obligó a los alemanes a prohibir la distribución de muchos de aquellos periódicos y a controlar la agitación política mediante Russkii Vestnik, editada en ruso por el estado mayor alemán. Desde finales de 1915 se distribuyeron más de 100.000 ejemplares dos veces por semana entre prisioneros y combatientes ${ }^{112}$. Trotsky llegó a decir de Russkii Vestnik que «solía hablar de los bolcheviques con una simpatía enternecedora» ${ }^{113}$. Retrataba la situación desesperada de la población civil en Rusia, a la vez que apelaba al deseo de llegar a una paz sin victoria $^{114}$. Sus objetivos eran fomentar el derrotismo y provocar el abandono ruso del frente, como hizo Nadelia, periódico editado por los austrohúngaros ${ }^{115}$.

La revolución precipitó la salida de Rusia de la guerra. Cinco meses después de tomar el poder, el gobierno soviético firmó con los Imperios Centrales una paz separada en Brest-Litovsk. El armisticio estipulaba la prohibición

108 PÖPPINGHEGE, 2007: 85-86.

$109 \mathrm{KOCH}, 1919: 277-279$.

${ }^{110}$ BECKER, 1998: 134-136.

111 RACHAMIMOV, 2002: 117.

112 WILLIAMS, 9/2, (Edmonton, 1967): 272-273.

113 TROTSKY, 1978: 379.

114 «Clever propaganda broke down Russia: Germans circulated a Newspaper in Prison Camps and Russian Trenches», The New York Times, 10 marzo de 1918.

${ }^{115}$ CORNWALL, 2000: 44. 
de distribuir propaganda entre los prisioneros, pero los bolcheviques pronto contravinieron aquel punto. Más de dos millones de internados en su territorio eran un contingente de inmenso valor militar que podía contribuir a consolidar su precario poder. La guerra civil estaba en ciernes y el aparato de agitación bolchevique se empleó a fondo para intentar ganarlos a su causa. En la primavera de 1918 comenzaron a circular entre los prisioneros los primeros periódicos en alemán y húngaro, exhortándoles a unirse al Ejército Rojo. Más adelante aparecieron en otros idiomas ${ }^{116}$. Hacia 1920 se habían editado alrededor de 200 diarios y revistas en una docena de lenguas ${ }^{117}$ o, lo que es lo mismo: más de tres millones de ejemplares ${ }^{118}$. Cerca de 100.000 soldados magiares, sin duda el colectivo más numeroso, lucharon junto a los bolcheviques durante la guerra civil ${ }^{119}$. Más allá de la significación política de aquella prensa, su lectura supuso para miles de hombres el primer contacto con su lengua escrita desde el inicio del cautiverio.

\section{CONCLUSIONES}

En las décadas previas a 1914, el aumento de la alfabetización y la adopción de hábitos propios de la cultura de masas contribuyeron a configurar un perfil de combatiente distinto al de cualquier conflicto anterior. Una vez iniciada la guerra, las autoridades militares asumieron ese perfil al permitir primero, y luego alentar, el envío de libros a las tropas. La misma asunción guió la decisión del CICR de incluir la distribución de lectura como una de las medidas con las que auxiliar a los prisioneros.

Destinar millones de libros y periódicos a los campos mostró la magnitud de la movilización material que exigía el esfuerzo bélico a los contendientes. Reveló además la dimensión cívica y ética de aquel fenómeno. No hubo fronteras para la solidaridad. Tanto en los países en guerra como en los neutrales surgieron organizaciones que articularon la colaboración desinteresada de la sociedad. La guerra, que había generado una cultura propia y tuvo en el internamiento de millones de hombres una de sus manifestaciones más brutales, no habría podido ocultar, como apunta Rémy Cazals ${ }^{120}$, una «cultura de tiempos de paz». El envío de libros y la organización de bibliotecas en los campos bien podrían ser ejemplos de esa cultura. Proporcionar lectura a los prisioneros, más allá de constituir un acto de generosidad, mostraría que eran vistos como civiles uni-

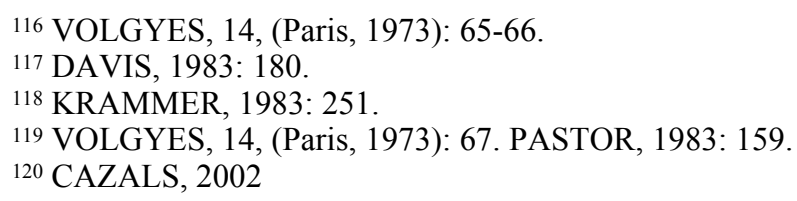


formados, preocupados por el retorno al trabajo y al estudio; y elaborarla para los propios compañeros de cautiverio, la prueba del sentimiento de un destino común compartido, además de un gesto de amor y camaradería. En el campo ruso de Voenny Gorodok, quienes sabían leer prepararon una cartilla de la que hicieron copias manuscritas para enseñar a los analfabetos y cumplir su ideal: que nadie que lo desease volviera a casa sin saber leer y escribir ${ }^{121}$. Leer no fue solo un instrumento para restituir parte de la humanidad que el conflicto había arrebatado a tantos hombres o una vía de escape ante el trauma de la reclusión, fue también una manifestación de sociabilidad propia de tiempos de paz.

Las alternativas de evasión dependieron de lo que leyeron los prisioneros. La movilización del libro religioso intentó hacer de su lectura un bálsamo para la herida moral que abrió la guerra y ahondó el cautiverio. Iglesias y organizaciones confesionales maniobraron con urgencia ante la necesidad de enfrentar aquel descalabro humano. La distribución masiva de Biblias, textos piadosos y libros de oración, supuso una acción tan caritativa como paternalista, bajo la que subyacía la pugna entre confesiones por capitalizar en su favor la vida espiritual de los campos. Sin embargo, aquellas lecturas no monopolizaron el interés de los prisioneros. El freno al progreso moral que supuso la guerra no debía implicar el freno al progreso individual. Para muchos hombres, más importante que obtener consuelo anímico fue prepararse para construir el futuro que traería la paz. Por eso el tiempo de internamiento lo emplearon en el estudio. Libros y bibliotecas contribuyeron a convertir algunos campos en universidades improvisadas. Leer para aprender fue un acto de libertad individual, constreñido por la censura y las vicisitudes de cada campo, pero, a la postre, una decisión consciente y voluntaria, puesta de manifiesto por las decenas de miles de peticiones personales de lectura.

En el cautiverio la guerra prosiguió por otros cauces y con otras armas, como la propaganda y el rumor. La prensa de los captores trató de influir en los prisioneros. Su mensaje transitó desde el interés por sembrar la desconfianza en la victoria, hasta el afán por ganar apoyos para la revolución social. Más allá de ser una alternativa a la prensa propagandística, los periódicos elaborados por los prisioneros fueron una de las expresiones más genuinas de la cultura generada por los combatientes. Reunieron al cronista y al lector, como sucedió con los periódicos de trinchera, a través de un relato capaz de mitigar la angustia del cautiverio y ofrecer otra vía de evasión.

${ }^{121}$ For the millions of men now under arms, 8, (New York, 1916): 24. 


\section{BIBLIOGRAFIA}

Amez, Benoît, Dans les tranchées, Paris, Publibook, 2009.

Audoin-Rouzeau, Stéphane y Becker, Annette, «Violence et consentement: la «culture de guerre» du premier conflit mundial», en Pour une histoire culturelle de Jean-Pierre Rioux, 1997.

Audoin-Rouzeau, Stéphane y Becker, Annette, 14-18 retrouver la guerre, Paris, Gallimard, 2000.

Audoin-Rouzeau, Stéphane, 14-18, les combattants des tranchées: à travers leurs journaux, Paris, A. Colin, 1968.

Audoin-Rouzeau, Stéphane; Becker, Annette, 14-18 retrouver la guerre, Paris, Gallimard, 2000.

Beaupin, E, «La Mission catholique suisse», Revue Internationale de la CroixRouge, 1/5, (Genève, 1919): 525-537.

Becker, Annette, Oubliés de la grande guerre, Paris, Noêsis, 1998.

Becker, Annette, «Faith, Ideologies, and the «Cultures of War» en John Horne (ed.) $A$ Companion to World War I, West Sussex, Blackwell Publishing, 2010; 234-247.

Becker, Jean Jacques, Histoire culturelle de la Grande Guerre, Paris, Armand Collin, 2005.

Becker, Jean-Jacques, Les soldats français pendant la guerre de 1914-1918 d'après les journaux de tranchées: une étude des mentalités, Paris, 1984.

Brändström, Elsa, Among Prisoners of War in Russia and Siberia, London, Hutchinson, 1928.

Bulletin International des Societes de la Croix-Rouge, 45/49 (Genève, 1914-1918).

Cazals, Rémy, «1914-1918: oser penser, oser écrire», Genèses, 46, (2002) : 26-43.

Cazals, Rémy y Loez, André, Dans les tranchées de 1914-18, Pau, Cairn, 2008.

Cornwall, Mark, The undermining of Austria-Hungary: the Battle for Hearts and Minds, London, MacMillann Press, 2000.

Cortés-Cabanillas, Julián. Alfonso XIII: vida, confesiones y muerte. Barcelona, Planeta, 1995.

Davis, Donald E., Trani, Eugene P., «The American YMCA and the Russian Revolution», Slavic Review, 33/3, (Champaign, 1974): 469-491.

Davis, Gerald H. «The life of Prisoners of War in Russia, 1914-1921», en Samuel R. Williamson y Peter Pastor, Essays on World War I: Origins and Prisoners of War, New York, Columbia University Press, 1983; 163-193.

Davis, Gerald H., «National Red Cross Societies and Prisoners of War in Russia, 1914-18», Journal of Contemporary History, 28/1, (1993): 31-52.

Dehérain, Henri, Les bibliothèques improvisées pendant la guerre, Paris, Imprimerie du Palais, 1919.

Duménil, Anne, Beaupré, Nicolas e Ingrao, Christian, 1914-1945. L’ère de la guerre, París, Agnes Vienot Editions, 2004. 
Durand, André, Histoire du Comité International de la Croix Rouge, Genève, Institut Henry-Dunant, 1978.

Fuchs, Thomas, Bibliothek und Militär, Frankfurt, Ph D. dissertation, 2008.

Fuller, John, Troop Morale and Popular Culture in the British and Dominion Armies, 1914-1918, Oxford, Oxford University Press, 1990.

Gatrell, Peter. «Prisoners of War on the Eastern Front during Wolrd War I», Kritika: Explorations in Russian and Eurasian History, 3/6, (Bloomington, 2005): 557566.

Geisendorf, M. y Des Gouttes, E, «L'Alliance Universelle des Unions chrétiennes de Jeunes Gens et son activités en faveur des prisonniers de guerre», Revue Internationale de la Croix-Rouge, 1/5, (Genève, 1919): 418-434.

Gerard, James, My Four Years in Germany, New York, George H. Doran, 1917.

González, Alfonso, «Soldados lectores. La movilización del libro durante la Gran Guerra», Zer, 16/30 (Lejona, 2011): 229-245.

Hagberg Wright, C.T., «Books for Russian Prisoners of War in Germany», Libraries: a monthly review of library matters and methods, 22, (Chicago, 1917): 274-276.

Harouel, Véronique, Histoire de la Croix Rouge, París, Presses Universitaires de France, 1999.

Hoffman, Conrad, In the Prison Camps of Germany: a Narrative of 'Y'Service among Prisoners of War, New York, Associated Press, 1920.

Isnenghi, Mario, Giornali di trincea 1915-1918, Torino, Eunadi, 1977.

Keegan, John, The First World War, New York, Alfred A. Knopf, 1999.

Kenez, Peter, The birth of the propaganda state: soviet methods of mass mobilization, 1917-1929, Cambridge, University Press, 1985.

Koch, Theodore Wesley, Books in camp, trench and hospital, [New York], [s.n.], 1917.

Koch, Theodore Wesley, Books in the war, New York, Houghton Mifflin Company, 1919.

Koulomzin, Sophie, Many worlds: a Russian life, New York, St. Vladimir's Seminary Press, 1980.

Krammer, Arnold, «Soviet propaganda among german and austro-hungarian prisoners of war in Russia, 1917-1921», en Samuel R. Williamson y Peter Pastor, Essays on World War I: Origins and Prisoners of War, New York, Columbia University Press, 1983; 239-264.

Krupskaya, Nadeshda, Mi vida con Lenin, Barcelona, Madrágora, 1976.

Langdon-Ford, Jean, «Prisoners of War like Library Users», Canadian Military History, 6/1, (1997): 92-96.

Laugesen, Amanda, Boredom is the enemy, London, Ashgate, 2011.

Meyer, Jacques, La vie quotidienne des soldats pendant la grande guerre, Paris, Hachette, 1966.

Morozzo, R., «I cappellani militari nella prima guerra mondiale», Rivista di storia contemporanea, 8/4, (Torino, 1979): 481-512. 
Muller, Marc, Les bibliothèques militaires dans le foyer du soldat, Paris, $\mathrm{Ph}$. D. dissertation, 2000.

Nachtigal, Reinhard, «German Prisoners of War in Tsarist Russia: A Glance at Petrograd», German History, 13/2, (1995): 198-204.

Nelson, Robert, German Soldier Newspapers of the First World War, Cambridge, Cambridge University Press, 2011.

Newcombe, Luxmoore, Winston, John H. E., «A prisoners of war library», The Library Association Record, 21, (London, 1919): 271-283.

Oxana, Nagorjana, Mankoff, Jeffrey, «United by Barbed Wire: Russian POWs in Germany, National Stereotypes, and International Relations, 1914-22», Kritika: Explorations in Russian and Eurasian History, 10/3, (Bloomington, 2009): 475-498.

Pando, Juan, Un rey para la esperanza: la España humanitaria de Alfonso XIII en la Gran Guerra, Madrid, Temas de Hoy, 2002.

Pastor, Peter, «Hungarian POWs in Russia During the Revolution and Civil War», en Samuel R. Williamson y Peter Pastor, Essays on World War I: Origins and Prisoners of War, New York, Columbia University Press, 1983; 149-162.

Pérez, Abelardo, «Mi cautiverio en Alemania», en José Subirá, Memorias y diarios: los españoles en la Guerra de 1914-1918, Madrid, Patronato de Voluntarios Españoles, 1922; 163-184.

Pope, Stephen; Wheal, Elizabeth-Anne, The Macmillan Dictionary of the First World War, London, Macmillan, 1995.

Pöppinghege, R, «The Battle of the Books: Supplying Prisoners of War», en Mary Hammond y Shafquat Towheed (eds), Publishing in the First World War, New York, Palgrave Macmillan, 2007; 78-91.

Powell, Joseph, Gribble, Francis, The History of Ruhleben: a Record of British Organisation in a Prison Camp in Germany, London, Collin Sons, 1919.

Prior, Robin; Wilson, Trevor, «War in the West, 1917-18» en John Horne (ed), $A$ Companion to World War I [en línea], Blackwell Publishing, 2010. Blackwell Reference Online. Disponible en: <http://www.blackwellreference.com/subscriber/ tocnode.html?id=g9781405123860_chunk_g978140512386020> [consulta: abril 2013].

Prost, Antoine «La guerre de 1914 n'est pas perdue», Le Mouvement Social, 199, (Paris, 2002), 95-102.

Rachamimov, Alon, POWs and the Great War: Captivity on the Eastern Front, Oxford, Berg, 2002.

Seal, Graham, The Soldiers' Press: Trench Journals in the First World War, London, Palgrave Macmillan 2013.

Showalter, Dennis, «War in the East and Balkans, 1914-18» en John Horne (ed), $A$ Companion to World War I [en línea], Blackwell Publishing, 2010. Blackwell Reference Online. Disponible en: <http:/www.blackwellreference.com/subscriber/ 
tocnode.html?id=g9781405123860_chunk_g978140512386020> [consulta: abril 2013].

Soudagne, Jean-Pascal, Le quotidien des soldats dans les tranchées, Paris, Soteca, 2009.

Strachan, Hew, The First World War, Oxford: Oxford Univesity Press, 2001.

Steuer, Kenneth, Pursuit of an 'Unparalleled Opportunity': The American YMCA and Prisoner of War Diplomacy among the Central Power Nations during World War I, 1914-1923, Irvington, Columbia University Press, 2008.

Stibbe, Matthew, «The Internment of Civilian by Belligerent States during the First World War and the Response of the International Committee of the Red Cross», Journal of Contemporary History, 41/1, (London, 2006): 5-19.

Strake, J., «Les catholiques allemandes et le service de secours pour prisonniers et disparus». Revue Internationale de la Croix-Rouge, 1/5, (Genève, 1919): 516-524.

Torras, Valentín, Un prisionero español de los alemanes, Madrid, Sociedad General Española de la Librería, 1916.

Trotsky, León, Mi vida, Madrid, Tebas, 1978.

Volgyes, Ivan, «Hungarian prisoners of war in Russia, 1916-1919», Cahiers du Monde Russe et Sovietique, 14, (Paris, 1973): 54-85.

Williams, Robert C., «Russian War Prisoners and Soviet-German Relations, 19181921», Canadian Slavonic Papers, 9/2, (Edmonton, 1967): 270-295.

Winter, Jay, «Demography» en John Horne (ed), A Companion to World War I [en línea], Blackwell Publishing, 2010. Blackwell Reference Online. Disponible en: $<$ http://www.blackwellreference.com/subscriber/tocnode.html?id=g9781405123860_ chunk_g978140512386020> [consulta: abril 2013].

Wurzer, Georg, Die Kriegsgefangenen der Mittelmächte in Rußland im Ersten Weltkrieg [en línea], Eberhard Karls Universität, Tübingen, 2000. Disponible en: http://w210.ub.uni-tuebingen.de/volltexte/2001/207/pdf/diss_wurzer.pdf [consulta: diciembre 2011].

Yanikdag, Yucel, «Ottoman Prisoners of War in Russia, 1914-22», Journal of Contemporary History, 34/1, (London, 1999): 69-85.

Yerly, Frédéric, «Grande guerre et diplomatie humanitaire. La mission catholique Suisse en faveur des prisonniers de guerre (1914-1918)», Vingtième Siècle. Revue d'histoire, 58/2, (Paris, 1998): 13-28.

Young, Arthur, Books for Sammies, Pittsburgh, Beta Phi Mu, 1981.

Recibido: 17/04/2012

Aceptado: 13/05/2013 